\title{
Expression of a Functional Recombinant Human Basic Fibroblast Growth Factor from Transgenic Rice Seeds
}

\author{
Na An ${ }^{1}$, Jiquan Ou ${ }^{2,3}$, Daiming Jiang ${ }^{2,3}$, Liping Zhang ${ }^{1}$, Jingru Liu ${ }^{2,3}$, Kai Fu ${ }^{1}$, Ying Dai ${ }^{2,3}$ and \\ Daichang Yang $1,2, *$
}

1 Engineering Research Center for Plant Biotechnology and Germplasm Utilization, Ministry of Education, State Key Laboratory of Hybrid Rice, College of Life Sciences, Wuhan University, Wuhan 430072, China; E-Mails: anna_8596@163.com (N.A.); zlp79717@yahoo.com.cn (L.Z.); alexfk1226@yahoo.cn (K.F.)

2 Wuhan Institute of Biotechnology, Biolake, Wuhan 430075, China;

E-Mails: jqou@oryzogen.com (J.O.); jdmay1986@126.com (D.J.); jingruliu@oryzogen.com (J.L.); dying@oryzogen.com (Y.D.)

3 Healthgen Biotechnology Ltd. Co., Biolake, Wuhan 430075, China

* Author to whom correspondence should be addressed; E-Mail: dyang@whu.edu.cn; Tel: +86-27-6875-4680; Fax: +86-27-6875-2163.

Received: 29 November 2012; in revised form: 22 January 2013 / Accepted: 31 January 2013 / Published: 7 February 2013

\begin{abstract}
Basic fibroblast growth factor (FGF-2) is an important member of the $F G F$ gene family. It is widely used in clinical applications for scald and wound healing in order to stimulate cell proliferation. Further it is applied for inhibiting stem cell differentiation in cultures. Due to a shortage of plasma and low expression levels of recombinant rbFGF in conventional gene expression systems, we explored the production of recombinant rbFGF in rice grains (Oryza sativa bFGF, OsrbFGF). An expression level of up to $185.66 \mathrm{mg} / \mathrm{kg}$ in brown rice was obtained. A simple purification protocol was established with final recovery of $4.49 \%$ and resulting in a yield of OsrbFGF reaching up to $8.33 \mathrm{mg} / \mathrm{kg}$ OsrbFGF. The functional assay of OsrbFGF indicated that the stimulating cell proliferation activity on $\mathrm{NIH} / 3 \mathrm{~T} 3$ was the same as with commercialized rbFGF. Wound healing in vivo of OsrbFGF is equivalent to commercialized rbFGF. Our results indicate that rice endosperm is capable of expressing small molecular mass proteins, such as bFGF. This again demonstrates that rice endosperm is a promising system to express various biopharmaceutical proteins.
\end{abstract}


Keywords: recombinant human bFGF; rice endosperm; protein expression and processing; cell proliferation and wound healing

\section{Introduction}

Fibroblast growth factors (FGFs) are a family of proteins that is structurally related to heparin-binding polypeptides with similar biological activities. To date, 23 different FGFs have been isolated [1]. A prototype of FGFs: i.e., bFGF (basic fibroblast growth factor, bFGF or FGF-2) was reported in the bovine brain in 1978 [2], and the first authentic purification of FGF-2 was carried out in 1984 [3]. It is a single-strand protein with a molecular weight of $\sim 17 \mathrm{kDa}$ and a pI of 9.6. It can stimulate the proliferation of NIH/3 3 cells and inhibit the differentiation of stem cells, and may play an important role in curing asthma because of its capacity for proliferation, migration and changing the contractile phenotypes of human airway smooth muscle cells in vitro [4]. Subsequently, bFGF has been found to stimulate the growth of mouse mammary epithelial cells [5]. In clinical applications it is widely used for acceleration of scald and wounding healing. Treatment of wounds showing redness, skin elevation and scald sealing with bFGF is superior to wounds caused by surgery, and there is also less skin hardness [6]. Therefore, bFGF is also used for effective tissue repair and wound healing of cardiovascular and neurodegenerative diseases.

bFGF was originally isolated from bovine brain and pituitary. Limited sources of bFGF make it difficult to meet the demand for the large amounts of bFGF required for both in vivo and in vitro applications. Over the past few decades, extensive efforts have been made to express recombinant human bFGF in E. coli, Pichia pastoris, soybean seeds, silkworm (Bombyx mori L.) and Bacillus subtilis [7-11]. Low yields, complicated processing and insolubility have been encountered when meeting the demand of the markets, especially, with an increasing number of applications for cell therapy and translational medicine. Recently, rice endosperm has been reported to express various recombinant pharmaceutical proteins, including human lactoferrin [12], human lysozyme [13], rhIGF-1 fusion, human granulocyte-macrophage colony stimulating factor [14] and human serum albumin [15]. These results showed that it is cost effective, safe, easy to scale-up and simpler to process than animal and other plant cell expression systems. Therefore, rice endosperm is considered to be a favorable expression platform for large-scale production of pharmaceutical proteins. The advantages are attractive for both research and industrial applications [16].

Here, we successfully expressed recombinant bFGF in rice (Oryza sativa) endosperm (OsrbFGF) with expression levels reaching $99.11-185.66 \mathrm{mg} / \mathrm{kg}$ of brown rice. A resulting yield of up to $8.33 \mathrm{mg} / \mathrm{kg}$ of brown rice, a purity $>95 \%$ and a $4.49 \%$ recovery were obtained. A simple purification protocol from rice seed was established. Further investigations indicate that OsrbFGF provides the same stimulation of NIH/3T3 cell proliferation. The purified OsrbFGF has the same efficacy of wound healing in vivo as other tested products. 


\section{Results}

\subsection{Generation and Selection of the Transgenic Lines for High Expression of OsrbFGF in Rice Seeds}

An endosperm-specific promoter from a glutelin gene $G t 13 a$ and its signal peptide were used in this study [14,17]. A human mature basic fibroblast growth factor (bFGF) gene was optimized with a rice codon bias. A total of 58 independent transformants was obtained using a two-strain Agrobacterium-mediated transformation [18] (Figure 1a). The positive transgenic plants were identified by polymerase chain reaction (PCR) analysis with specific primers (Figure 1b). Western blotting indicated that 35 (63.34\%) transformants accumulated OsrbFGF in the rice endosperm (Figure 1c). The expression level of total OsrbFGF ranged from 99.11 to $185.66 \mathrm{mg} / \mathrm{kg}$ of brown rice from eight lines with high fertility (Figure 1d). Transgenic lines, 277-122 and 277-238, were the highest expressing lines and were used for further study.

Figure 1. Generation and screening of the transgenic plants highly expressing recombinant basic fibroblast growth factor (bFGF) in rice (Oryza sativa) endosperm (OsrbFGF): (a) Maps of plasmids of $p O S P M P 277$ and $p O s P M P 05$; (b) Agarose gel for screening positive transgenic lines by polymerase chain reaction (PCR) amplification with primers $F 1$ and R1 and (c) identification of the transgenic lines from T1 seed expressing OsrbFGF by Western blotting; (d) Quantitation of expression levels of the individual T1 transgenic seeds. Lane M, marker; Lane 1, 277-45; Lane 2, 277-47; Lane 3, 277-53; Lane 4, 277-75; Lane 5, 277-122; Lane 6, 277-179; Lane 7, 277-223; Lane 8, 277-238; Pc, plasmid pOsPMP277 (b) and $350 \mathrm{ng}$ of recombinant bFGF from E. coli (c); Nc, wild type TP309 DNA (b) and crude protein extracts from the seed of wild type TP309 (c).
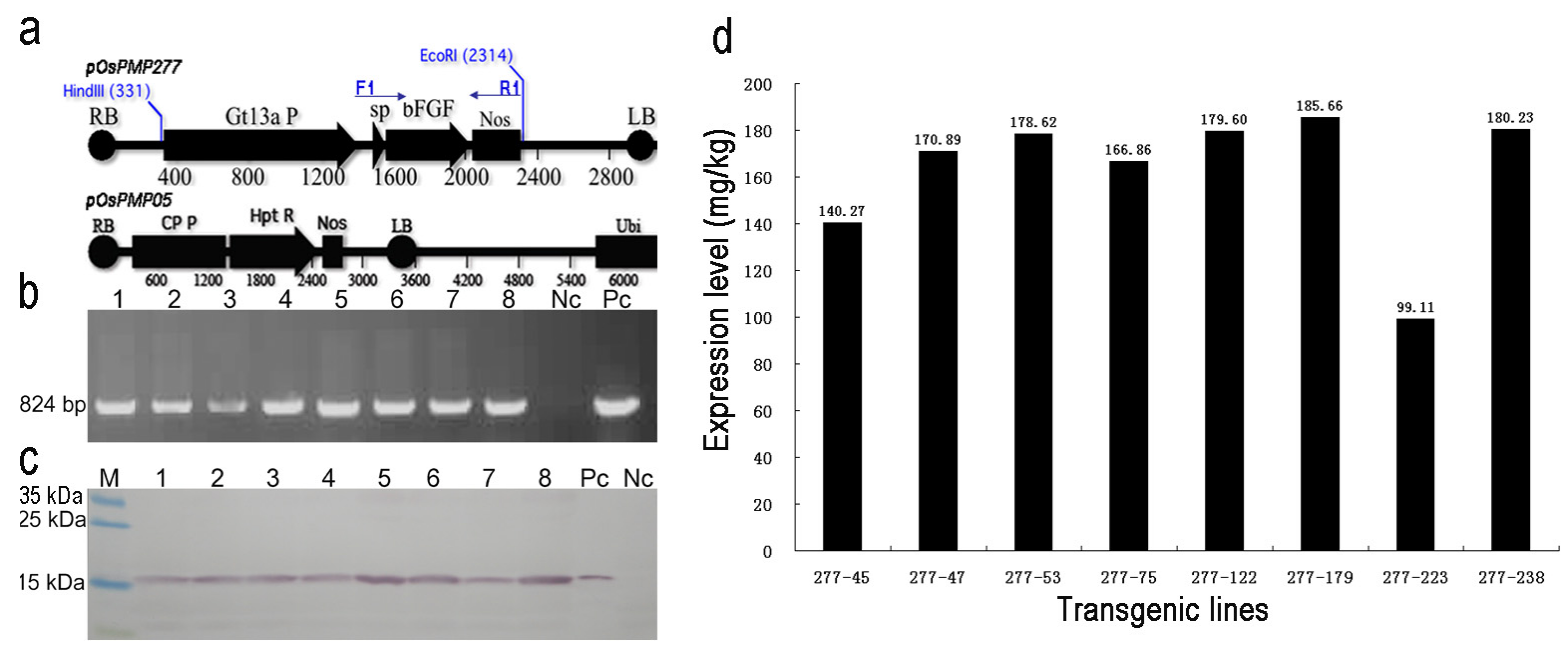

\subsection{Genetic Analysis of the Transgenic Lines and Characterization of OsrbFGF}

The segregation for transgene expression was determined in the $\mathrm{T} 1$ seeds of the transgenic lines 277-238, 277-223, 277-122 and 277-179, genetic segregation in T1 seeds based on the expression: non-expression was analyzed. The results showed that 277-238, 277-223 and 277-179 showed a single locus and 277-122 two loci (Figure 2a). Southern blotting was carried out for further characterization of copy numbers in these transgenic lines. The results indicated that one fragment from transgenic lines 
277-238 and 277-223 was detected by digestion of either EcoRI or HindIII, which is consistent with the results from genetic segregation. Digestion with EcoRI and HindIII of 277-122 yielded three fragments and two fragments, respectively. The results of genetic segregation and Southern blots of 277-122 indicated that it contained two loci. Although the transgenic line 277-179 showed two loci when digested with EcoRI or HindIII, the fragment obtained with HindIII was of smaller size to the entire expression cassette obtained with double digestion with HindIII/EcoRI. This suggested that it was a truncated locus. This further explained why 277-179 yielded two loci with Southern blotting, while genetic segregation of expression indicated a single locus (Figure 2a,b). To further determine whether rice endosperm cells can properly cleave the signal peptide at the $N$-terminus of OsrbFGF, $N$-terminal analysis was carried out and revealed that two amino acids, Met and Ala, were missing at the $N$-terminus of OsrbFGF (Figure 2c).

Figure 2. Genetic analyses of the transformants by transgene segregation and Southern blotting: (a) Genetic segregation of $\mathrm{T}_{1}$ seeds from transgenic lines; (b) Southern blot analysis of four transgenic lines and TP309. Genomic DNA was digested with EcoRI or HindIII and EcoRI/HindIII, and plasmid pOsPMP277 and wild type TP309 genomic DNA were digested with EcoRI/HindIII. Lane 1, 277-122; Lane 2, 277-179; Lane 3, 277-223; Lane 4, 277-238; M, marker (Lambda DNA digested by HindIII); Pc, positive control (pOsPMP277 DNA with length of 1983bp); Nc, negative control (Wild-type TP309 genomic DNA); (c) Amino acid sequences of the signal peptide and OsrbFGF. The signal peptide is underlined and two missed amino acids (Met and Ala) are in bold.

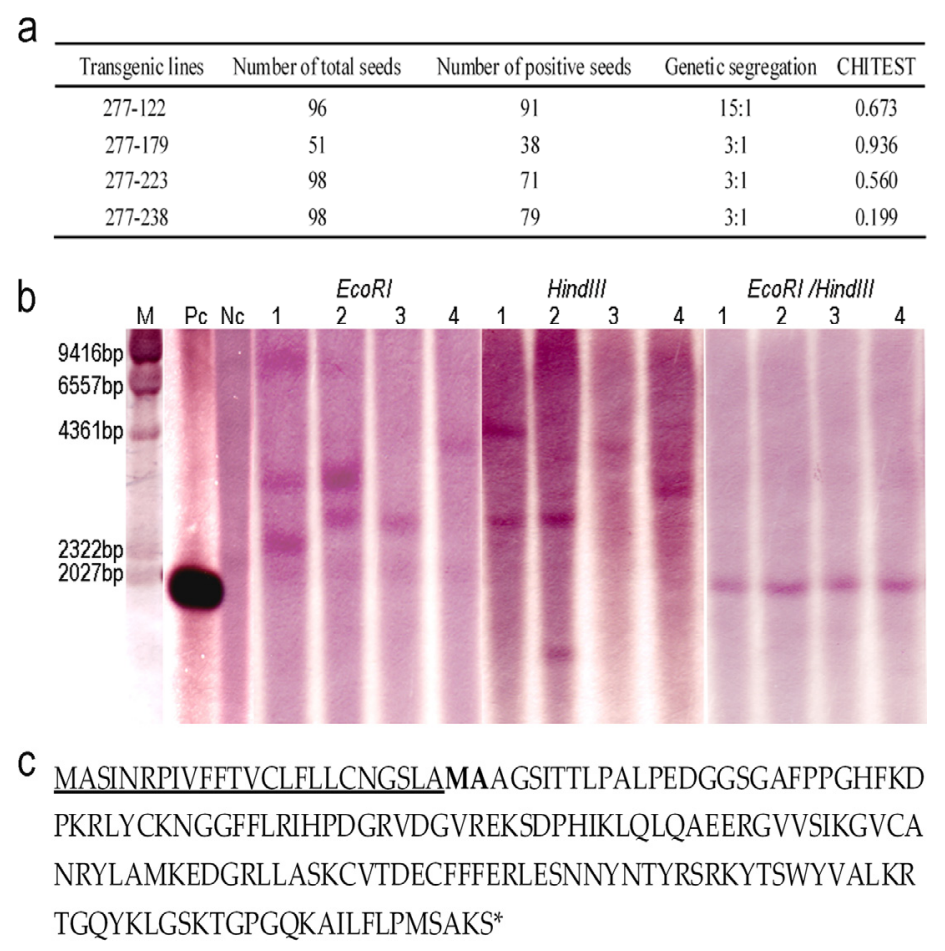

\subsection{Purification of OsrbFGF from Transgenic Rice Seeds}

After the highly expressing OsrbFGF transgenic lines were identified, we developed a purification protocol for large scale processing of OsrbFGF that could satisfy the demand of the markets. We firstly 
tried to separate the impurities using different ion exchange resins from rice seeds; however, all efforts failed (data not shown). Then we tried direct application of a heparin affinity column and washing with two different buffers that removed most of the impurities from the affinity column. A high purity OsrbFGF with a single band of $17 \mathrm{kDa}$ was obtained (Figure 3). Endotoxin contamination was removed with one step of ultrafiltration using $5 \mathrm{kDa}$ or $100 \mathrm{kDa}$ filters. The resulting purity of OsrbFGF reached up to $>95 \%$ and $<1 \mathrm{EU} / \mu \mathrm{g}$, respectively. The final yield of OsrbFGF was $8.33 \mathrm{mg} / \mathrm{kg}$ of brown rice with a recovery of $4.49 \%$.

Figure 3. Purification of OsrbFGF from the seeds derived from transgenic line 277-179. (a) The recovery rate of OsrbFGF for purification step; (b) sodium dodecyl sulfate polyacrylamide gel electrophoresis (SDS-PAGE) with Coomassie blue G250 staining for each processing step; (c) Western blotting analysis of each processing step. Extra: the crude extraction; W1: wash 1; W2: wash 2; Elu: Elutant; UF-5: ultrafiltration in size of $5 \mathrm{kDa}$; M: molecular mass marker.

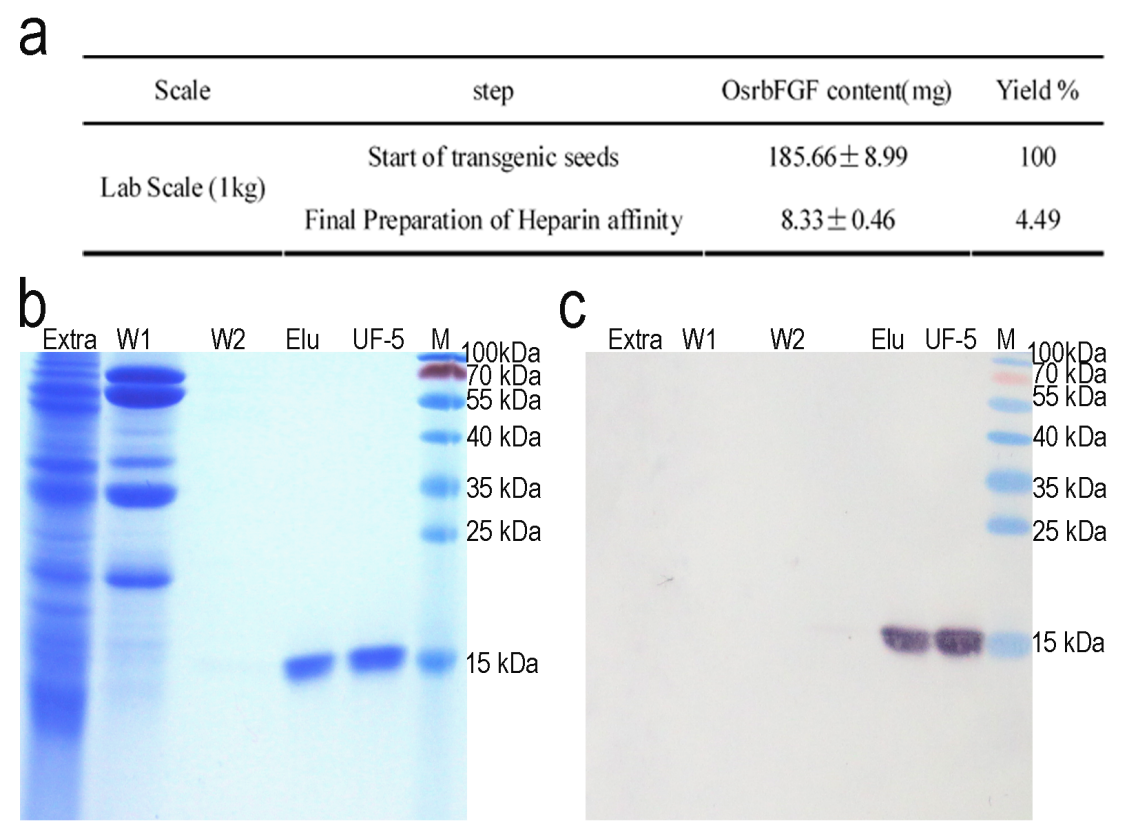

\subsection{OsrbFGF Can Effectively Stimulate NIH/3T3 Cell Proliferation}

The NIH/3T3 cell line is generally used for evaluation of the biological activity of FGFs [19]. To evaluate the biological activity of OsrbFGF, stimulation of NIH/3T3 cells proliferation was tested. As shown in Figure 4a, OsrbFGF concentrations from 0.0007 to $12.5 \mathrm{IU} / \mathrm{mL}$ showed a dose-dependent cell proliferative effect on NIH/3T3 cells, reaching $1.04 \times 10^{6} \mathrm{IU} / \mathrm{mg}$. The result suggests that OsrbFGF has the same stimulation of cell proliferation as commercialized rbFGF.

\subsection{OsrbFGF Has Equivalent Efficacy in Wound Healing}

bFGF is used for would healing therapy [20]. To evaluate its biological activities in vivo, OsrbFGF was applied to a mouse cut model for wound healing. Three dosages of OsrbFGF; i.e., $125 \mathrm{ng} / \mathrm{treatment}$, $500 \mathrm{ng} /$ treatment and $2000 \mathrm{ng} /$ treatments were tested. Wound healing rates were observed on Day 0 , Day 2, Day 4, Day 6, Day 8, Day 10, Day 12 and Day 14 after wound treatments. The results indicated 
that wound healing rates were dose-dependent. The efficacy of stimulating wound healing at a low-dose was more significant than that of $500 \mathrm{ng}$ and $2000 \mathrm{ng}$ within eight days after treatment (Figure 4b). In general, the recovery of wounded skin could promote epithelialization, increase expression of the CD68 and proliferation of cell nuclear antigen (PCNA) [21]. We therefore monitored the expression of PCNA and CD68 on the wound area on Day 3, Day 7 and Day 14 treatments from a dosage of 500 ng OsrbFGF. The results showed that CD68 and PCNA in the OsrbFGF treatments were increased significantly compared to that of the negative control on Day 3 and Day 7 of post-wound healing and was lower than that of post-wound healing in the control group on Day 14 (Figure 4d,f). The results indicated that OsrbFGF could accelerate wound healing by stimulating cell proliferation and improving the expression of CD68 and PCNA in the early stage of treatment. It then decreased the expression to prevent the generation of scars and cell proliferation when the wound closed at the late stage of the treatment.

Figure 4. Biological activity assay of OsrbFGF in vitro and in vivo. (a) The cell proliferation assay of OsrbFGF with NIH/3T3 cells; (b) Wound healing rate on Day 2, Day 4, Day 6, Day 8, Day 10, Day 12 and Day 14. The diagrams of the positive cells of CD68 (c) and proliferation of cell nuclear antigen (PCNA) (e) on Day 3, Day 7 and Day 14 ( $t$-test $* p<0.05, * * p<0.01)$. The microimages of immune autoradiography of (d) CD68 and (f) PCNA (x40). For the immunohistochemistry assay, a dosage of $500 \mathrm{ng}$ OsrbFGF was chosen and the positive cells with CD68 and PCNA were counted. NS means normal saline.

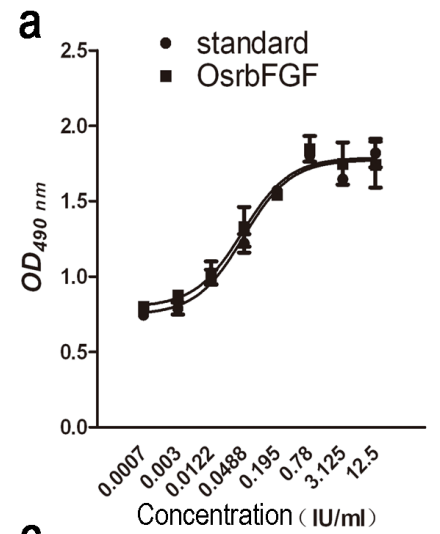

$\mathbf{C}_{800}$
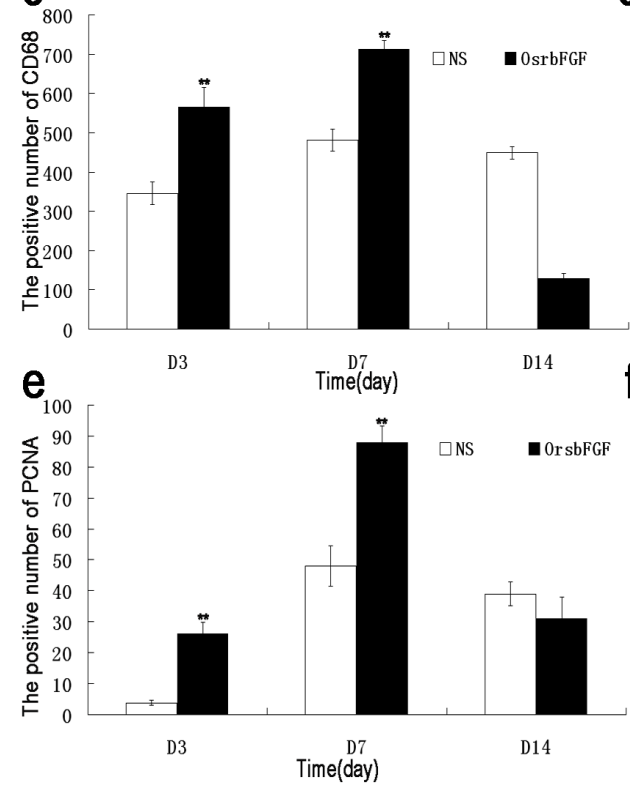

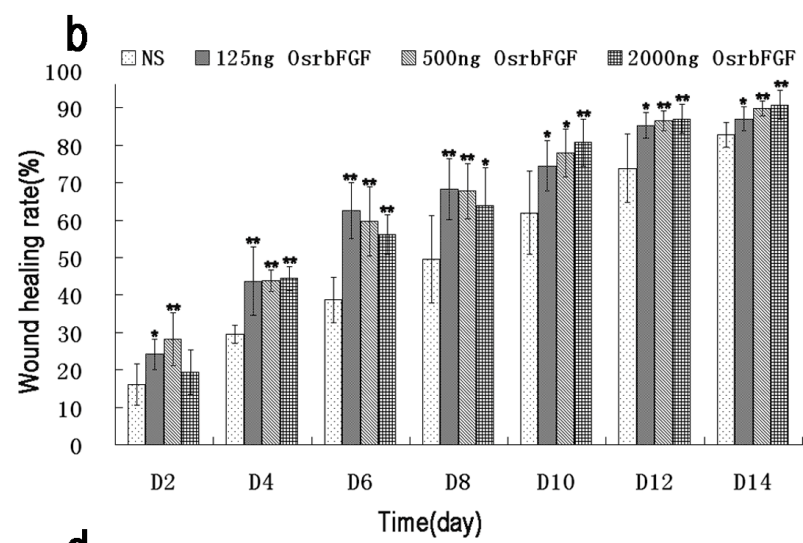

d
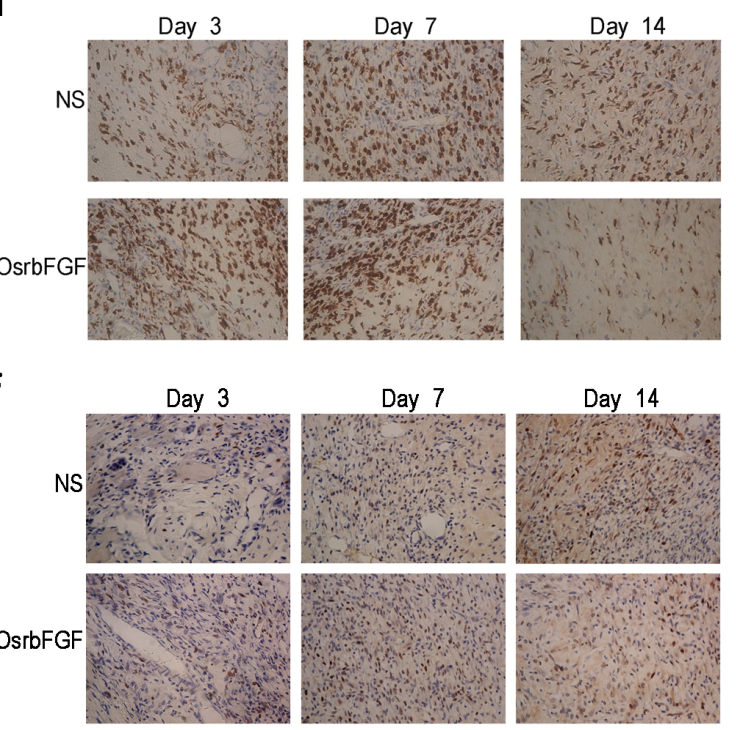

Day 3

Day 7

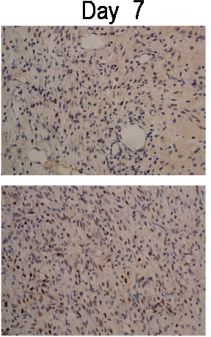

Day 14

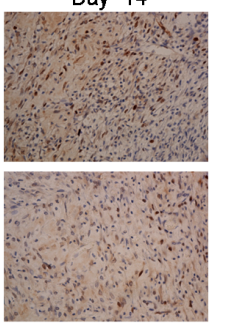




\section{Discussion}

In general, small growth factors are usually difficult to express in current expression systems because they have a small molecular mass. Our study demonstrated that rice endosperm cells as bioreactors successfully expressed functional OsrbFGF and that the expression levels of total OsrbFGF reached up to $185.66 \mathrm{mg} / \mathrm{kg}$ in brown rice, of which $17.74 \mathrm{mg} / \mathrm{kg}$ was soluble OsrbFGF accounting for 9.55\% of total OsrbFGF (data not shown). The yield was two- to four-fold higher than that in E. coli, Bacillus subtilis, insect cell and yeast (Saccharomyces cerevisiae) systems [7,8,22,23], but lower than that in Pichia pastoris systems[11]. Although only $4.49 \%$ of the total OsrbFGF was recovered due to the insolubility of OsrbFGF, the resulting yield still reached $8.33 \mathrm{mg} / \mathrm{kg}$ in brown rice, which was significantly higher than the required threshold for commercialization. Furthermore, we successfully developed a simple purification protocol to isolate OsrbFGF from rice grains, demonstrating that rice grains have the advantages over other systems for recombinant protein processing. In addition, two amino acids at the $N$-terminus of OsrbFGF were deleted but the protein retained the same biological functions both in vitro and in vivo. This suggested that the two amino acids at the $N$-terminus were not essential for its function.

In previous reports, rice endosperm cells have been demonstrated to be capable of expressing various pharmaceutical proteins $[12-15,17]$. Our results showed that rice endosperm cells had the capability of expressing proteins with special features of proteins, such as small molecular mass and hydrophobic proteins. Most of the OsrbFGF was soluble when detergent and reduced reagents were used, which implied that OsrbFGF could be misfolded or aggregated. To solve this problem, one approach could be via co-expression of molecular chaperons to promote help with exogenous protein folding and to prevent aggregation. Most transgenic endosperms with high recombinant protein expression developed endoplasmatic reticulum (ER) stress [24]. Another approach to increase the solubility of recombinant proteins in rice endosperm cells could be to decrease the expression of endogenous storage proteins to alleviate the ER stress.

\section{Experimental Procedures}

\subsection{Plasmid Construction and Rice Transformation}

pOsPMP02 was used to construct an endosperm-specific expression cassette [14]. The coding sequence of the human $b F G F$ gene (Genbank accession No. NM 002006) was synthesized by Heron Blue Biotechnology Inc. (Bothell, WA, USA) using rice-preferred genetic codons. The synthesized gene was cleaved by $S c h \mathrm{I}$ and $X h o \mathrm{I}$ and then cloned into $p O S P M P 02$ to produce $p O s P M P 276$. A binary vector for Agrobacterium-mediated transformation was produced by digesting $p O s P M P 276$ with HindIII and $E c o$ RI and an entire expression cassette with a 1983-bp fragment containing the Gt13a promoter and the signal peptide, codon optimized $b F G F$ gene and Nos terminator was inserted into a binary vector $J H 2600$ [25]. The resulting binary plasmid was designated as $p O s P M P 277$. The binary plasmid was transferred into the Agrobacterium tumefaciens strain EHA105 harboring plasmid pOsPMP05 containing a selective marker gene [14], and $p O s P M P 277$ were co-transformed into the calli regenerated from a rice variety TP309 by the Agrobacterium-mediated transformation as described previously [26]. 


\subsection{Screening for High Expressing OsrbFGF Transgenic Lines and Determination of the Expression Level}

To screen the positive transgenic lines, a forward primer F1 (5'-GAGGGTGTGGAGGCTCTTGT-3') from the Gt13a signal peptide and a reverse primer R1 (5'-GCCAGTGAATTCCCGATCTAGTAAC-3') from the Nos terminator were used for PCR amplification.

To obtain the expression levels of transgenic lines, Western blot was used. Briefly, $100 \mathrm{mg}$ of $\mathrm{T} 1$ seeds from a PCR positive transgenic plant were ground with $1 \mathrm{~mL}$ of extraction buffer $(66 \mathrm{mM}$ Tris-HCl, pH 6.8, 2\% SDS, $1 \mathrm{mM}$ dithiothreitol (DTT)), and then centrifuged at 10,620× $g$ for $10 \mathrm{~min}$. Fifteen micrograms of the crude protein extracts and $350 \mathrm{ng}$ of recombinant bFGF derived from E. coli were separated by a $15 \%$ SDS-PAGE gel and then transferred to a nitrocellulose membrane. A rabbit polyclonal to bFGF (Abcam, Cambridge, UK) in a dilution of 1:2000 and alkaline phosphatase goat anti-rabbit IgG (ZSGB-BIO, Beijing, China) in a dilution of 1:10000 were used. Detection of target protein was carried out using the substrates p-Nitro-Blue Tetrazolium Chloride and 5-Bromo-4-Chloro-3-Indolyl Phosphate (BIOSHARP, Hefei, China). Immunoblotting procedures were performed as described previously [17]. The expression level was determined from Western blotting by the Image-pro Plus software. Briefly, four concentrations of $50 \mathrm{ng}, 100 \mathrm{ng}, 200 \mathrm{ng}$ and $400 \mathrm{ng}$ of rbFGF derived from $E$. coli were used for quantitation of OsrbFGF level. The density of each known concentrations of rbFGF in Western blot was obtained by Image-pro Plus software. The expression level of each transgenic line was calculated based on the equation $y=2.0018^{*}-118.05\left(R^{2}=0.98722\right)$.

\subsection{Southern Blotting}

About 200 milligrams of young leaf were ground with liquid nitrogen, and genomic DNA extraction was carried out using a TIANGEN DNA Quick Plant System (TIANGEN Biotech, Beijing, China). Genomic DNA was digested with EcoRI, HindIII, or EcoRI/HindIII (New England Biolabs, Ipswich, MA, USA), respectively, at $37^{\circ} \mathrm{C}$ overnight and then was separated by $0.8 \%$ agarose gel. After transfer to a MILLIPORE NY + membrane, hybridization was carried out following the instructions of Roche DIG High Prime DNA Labeling and Detection Starter Kit I. A probe with an 824 bp fragment derived from the $b F G F$ encoding region was prepared by amplifying with the primers $\mathrm{F} 1$ and $\mathrm{R} 1$.

\subsection{OsrbFGF Purification}

The transgenic rice seeds were ground and extracted $(1: 5, w / v)$ with the extraction buffer $(50 \mathrm{mM}$ phosphate buffer, $\mathrm{pH} 7.5,1 \mathrm{mM}$ EDTA, $1 \mathrm{mM}$ reduced L-Glutathione, $250 \mathrm{mM} \mathrm{NaCl}$ ) for $1 \mathrm{~h}$ at room temperature. Then, the crude extract was clarified by the following $3 \mu \mathrm{m}$ and $0.22 \mu \mathrm{m}$ filtration through a positive pressure filter, respectively. Subsequently, the filtrate was applied onto the heparin 6 fast flow (GE Healthcare, www.gelifesciences.com) column equilibrated with $50 \mathrm{mM}$ phosphate buffer ( $\mathrm{pH}$ 7.5) containing $250 \mathrm{mM} \mathrm{NaCl}$ and $1 \mathrm{mM}$ reduced L-glutathione. Two wash steps were used to remove the impurity proteins and increase the OsrbFGF recovery. Wash buffer 1 (50 mM phosphate buffer ( $\mathrm{pH} 7.5)$, $600 \mathrm{mM} \mathrm{NaCl}, 1 \mathrm{mM}$ reduced L-glutathione) and Wash buffer 2 (50 mM phosphate buffer (pH 7.5), $900 \mathrm{mM} \mathrm{NaCl}, 1 \mathrm{mM}$ reduced L-glutathione) were used to remove impurities. After washing, the OsrbFGF was eluted by elution buffer $(10 \mathrm{mM}$ Tris- $\mathrm{HCl}(\mathrm{pH} 7.5), 1.7 \mathrm{mM} \mathrm{NaCl}, 1 \mathrm{mM}$ reduced 
L-glutathione). Before lyophilization, the OsrbFGF elution was concentrated and partially desalted using a $5 \mathrm{kD}$ ultrafiltration filter with Pellicon XL (Millipore, Billerica, MA, USA), and then endotoxins were removed by a $100 \mathrm{kD}$ ultrafiltration filter with a Viva Flow 50 (Sartorius, Goettingen, Germany). Finally, OsrbFGF was lyophilized with the protection of OsrHSA (1:50,w/w) [15]. The final protein concentration was determined using the Coomassie Plus (Bradford) Assay Kit (Thermo Fisher Scientific Inc., Rockford, IL, USA).

\subsection{N-terminal Sequence Analysis}

The purified OsrbFGF was transferred to a polyvinylidene difluoride (PVDF) membrane and then put into a protein sequencer PPSQ-31A (Shimadzu Cooperation, Kyoto, Japan) reactor to run 15 cycles.

\subsection{MTT Assay}

The mitogenic activity of OsrbFGF was assessed through NIH/3T3 cell proliferation using the methylthiazoletetrazolium (MTT) method. NIH/3T3 cells were seeded in flat-bottom, 96-well plates at an initial density of $2 \times 10^{5}$ cells per $\mathrm{mL}(200 \mu \mathrm{L}$ per well) and cultured in Dulbecco's modified eagle minimum essential medium (DMEM) supplemented with 10\% FBS for $24 \mathrm{~h}$ and then cultured in fresh maintenance DMEM containing $0.75 \%$ FBS for $24 \mathrm{~h}$. After the medium was removed, $200 \mu \mathrm{L}$ maintenance medium containing a four-fold serial dilution of OsrbFGF or the recombinant bFGF standard with the initial concentration of $50 \mathrm{IU} / \mathrm{mL}$ was added into the wells and the cells were incubated for $48 \mathrm{~h}$. The number of viable cells was determined by adding $20 \mu \mathrm{L}$ methylthiazoletetrazolium (MTT $5 \mathrm{mg} / \mathrm{mL}$ ) to each well. The culture was incubated for $4 \mathrm{~h}$. After removal of the media, $150 \mu \mathrm{L}$ dimethyl sulfoxide (DMSO) was added to each well. The plate was kept at room temperature for $30 \mathrm{~min}$ and was measured at $490 \mathrm{~nm}$ in a VersaMax $400 \mathrm{~nm}$ (Molecular Devices, Sunnyvale, CA, USA). All the data were analyzed with the GraphPad software. All experiments were repeated three times.

\subsection{Wound Healing Assay}

Female Sprague-Dawley rats (SD) with 200-250 g of body weight were obtained from Shanghai Slac Laboratory Animal Co. Ltd. The SD rats were randomly divided into four groups, and the excisional wound splinting model was generated as described previously [27]. Three dosages of OsrbFGF of $2000 \mathrm{ng} / \mathrm{mL}(n=15), 500 \mathrm{ng} / \mathrm{mL},(n=15), 125 \mathrm{ng} / \mathrm{mL},(n=15)$ and negative control with normal saline $(n=15)$ were designed for testing the healing rates. The wound healing rate $=($ Area of original wound Area of actual wound)/Area of original wound $\times 100$.

\subsection{Immunohistochemistry Assay}

For the immunohistochemistry assay, a dosage of $500 \mathrm{ng}$ OsrbFGF was chosen. Fixation, sectioning and immuno-electronic microscopic observations followed the procedure as previously described [28]. A mouse antibody against CD68 or PCNA in a dilution of 1:100 and a goat anti-mouse IgG-HRP in a dilution of 1:200 were used. Finally, each slide was stained with the diaminobenzidine (DAB) substrate. After immunofluorescence staining, CD68 or PCNA positive cells were counted from three fields per section at the wound site between the edges in six successive sections. 


\section{Conclusions}

We successfully expressed functional recombinant bFGF (Oryza sativa bFGF, OsrbFGF) in rice endosperm cells and established a simple purification protocol with single step processing. The results indicate that the stimulating cell proliferation activity on NIH/3T3 of OsrbFGF and the acceleration of wound healing in vivo are comparable to commercialized rbFGF. Our results indicate that rice endosperm is capable of expressing high hydrophobic proteins, such as bFGF. Our data again demonstrates that rice endosperm is a promising system to express various biopharmaceutical proteins.

\section{Acknowledgements}

We are grateful to Wenzhou Medical College for the wound healing assay and Sci-Longs Biotech Inc. for N-terminal analysis. This work was supported by the National High-tech R\&D Program (863 Program) of China (No. 2011AA100604), Major Projects of Genetically Modified Crop of China (No. 2011ZX08001-006) and Biolake, National Biological Industry Base in Wuhan, China. We also thank Prof. Diter von Wettstein for critical reading of the manuscript.

\section{References}

1. Yamashita, T.; Yoshioka, M.; Itoh, N. Identification of a novel fibroblast growth factor, FGF-23, preferentially expressed in the ventrolateral thalamic nucleus of the brain. Biochem. Biophys. Res. Commun. 2000, 277, 494-498.

2. Gospodarowicz, D.; Bialecki, H.; Greenburg, G. Purification of the fibroblast growth factor activity from bovine brain. J. Biol. Chem. 1978, 253, 3736-3743.

3. Bohlen, P.; Baird, A.; Esch, F.; Ling, N.; Gospodarowicz, D. Isolation and partial molecular characterization of pituitary fibroblast growth factor. Proc. Natl. Acad. Sci. USA 1984, 81, 5364-5368.

4. Zou, H.; Nie, X.; Zhang, Y.; Hu, M.; Zhang, Y.A. Effect of basic fibroblast growth factor on the proliferation, migration and phenotypic modulation of airway smooth muscle cells. Chin. Med. J. Peking 2008, 121, 424-429.

5. Lavandero, S.; Chappuzeau, A.; Sapag-Hagar, M.; Oka, T. In vivo and in vitro evidence of basic fibroblast growth factor action in mouse mammary gland development. FEBS Lett. 1998, 439, 351-356.

6. Akita, S.; Akino, K.; Imaizumi, T.; Hirano, A. A basic fibroblast growth factor improved the quality of skin grafting in burn patients. Burns 2005, 31, 855-858.

7. Kwong, K.W.Y.; Ng, K.L.; Lam, C.C.; Wang, Y.Y.; Wong, W.K.R. Authentic human basic fibroblast growth factor produced by secretion in bacillus subtilis. Appl. Microbiol. Biotechnol. 2012, doi:10.1007/s00253-012-4592-0.

8. Ke, Y.; Wilkinson, M.C.; Fernig, D.G.; Smith, J.A.; Rudland, P.S.; Barraclough, R. A rapid procedure for production of human basic fibroblast growth factor in Escherichia coli cells. BBA Gene Struct. Expr. 1992, 1131, 307-310. 
9. Wu, X.; Kamei, K.; Sato, H.; Sato, S.; Takano, R.; Ichida, M.; Mori, H.; Hara, S. High-level expression of human acidic fibroblast growth factor and basic fibroblast growth factor in silkworm (Bombyx mori L.) using recombinant baculovirus. Protein Expres. Purif. 2001, 21, 192-200.

10. Ding, S.H.; Huang, L.Y.; Wang, Y.D.; Sun, H.C.; Xiang, Z.H. High-level expression of basic fibroblast growth factor in transgenic soybean seeds and characterization of its biological activity. Biotechnol. Lett. 2006, 28, 869-875.

11. Mu, X.; Kong, N.; Chen, W.; Zhang, T.; Shen, M.; Yan, W. High-level expression, purification, and characterization of recombinant human basic fibroblast growth factor in pichia pastoris. Protein Expres. Purif. 2008, 59, 282-288.

12. Suzuki, Y.A.; Kelleher, S.L.; Yalda, D.; Wu, L.; Huang, J.; Huang, N.; Lönnerdal, B. Expression, characterization, and biologic activity of recombinant human lactoferrin in rice. J. Pediatr. Gastr. Nutr. 2003, 36, 190-199.

13. Yang, D.; Guo, F.; Liu, B.; Huang, N.; Watkins, S.C. Expression and localization of human lysozyme in the endosperm of transgenic rice. Planta 2003, 216, 597-603.

14. Ning, T.; Xie, T.; Qiu, Q.; Yang, W.; Zhou, S.; Zhou, L.; Zheng, C.; Zhu, Y.; Yang, D. Oral administration of recombinant human granulocyte-macrophage colony stimulating factor expressed in rice endosperm can increase leukocytes in mice. Biotechnol. Lett. 2008, 30, 1679-1686.

15. He, Y.; Ning, T.; Xie, T.; Qiu, Q.; Zhang, L.; Sun, Y.; Jiang, D.; Fu, K.; Yin, F.; Zhang, W. Large-scale production of functional human serum albumin from transgenic rice seeds. Proc. Natl. Acad. Sci. USA 2011, 108, 19078-19083.

16. Ramessar, K.; Capell, T.; Christou, P. Molecular pharming in cereal crops. Phytochem. Rev. 2008, 7, 579-592.

17. Xie, T.; Qiu, Q.; Zhang, W.; Ning, T.; Yang, W.; Zheng, C.; Wang, C.; Zhu, Y.; Yang, D. A biologically active rhIGF-1 fusion accumulated in transgenic rice seeds can reduce blood glucose in diabetic mice via oral delivery. Peptides 2008, 29, 1862-1870.

18. Daley, M.; Knauf, V.C.; Summerfelt, K.R.; Turner, J.C. Co-transformation with one agrobacterium tumefaciens strain containing two binary plasmids as a method for producing marker-free transgenic plants. Plant Cell Rep. 1998, 17, 489-496.

19. Gospodarowicz, D. Localisation of a fibroblast growth factor and its effect alone and with hydrocortisone on 3T3 cell growth. Nature 1974, 249, 123-127.

20. McGee, G.S.; Davidson, J.M.; Buckley, A.; Sommer, A.; Woodward, S.C.; Aquino, A.M.; Barbour, R.; Demetriou, A.A. Recombinant basic fibroblast growth factor accelerates wound healing. J. Surg. Res. 1988, 45, 145-153.

21. Eming, S.A.; Hammerschmidt, M.; Krieg, T.; Roers, A. In Interrelation of immunity and tissue repair or regeneration. Semin. Cell Dev. Biol. 2009, 20, 517-527.

22. Yamei, W.; Licui, S.; Yahui, Q.; Yang, S.; Yudong, Y.; Hong, Y.; Jingyi, Z. Expression of human basic fibroblast growth factor gene in sf9 insect cell. J. Cap. Univ. Med. Sci. 2004, 25, 431-434.

23. Barr, P.J.; Cousens, L.S.; Lee-Ng, C.T.; Medina-Selby, A.; Masiarz, F.R.; Hallewell, R.A.; Chamberlain, S.H.; Bradley, J.D.; Lee, D.; Steimer, K.S. Expression and processing of biologically active fibroblast growth factors in the yeast Saccharomyces cerevisiae. J. Biol. Chem. 1988, 263, 16471-16478. 
24. Luo, J.; Ning, T.; Sun, Y.; Zhu, J.; Zhu, Y.; Lin, Q.; Yang, D. Proteomic analysis of rice endosperm cells in response to expression of hGM-CSF. J. Proteome Res. 2008, 8, 829-837.

25. Hennegan, K.; Yang, D.; Nguyen, D.; Wu, L.; Goding, J.; Huang, J.; Guo, F.; Huang, N.; Watkins, S.C. Improvement of human lysozyme expression in transgenic rice grain by combining wheat (Triticum aestivum) puroindoline $\mathrm{b}$ and rice (Oryza sativa) Gt1 promoters and signal peptides. Transgenic Res. 2005, 14, 583-592.

26. Yang, D.; Wu, L.; Hwang, Y.S.; Chen, L.; Huang, N. Expression of the reb transcriptional activator in rice grains improves the yield of recombinant proteins whose genes are controlled by a reb-responsive promoter. Proc. Natl. Acad. Sci. USA 2001, 98, 11438-11443.

27. Galiano, R.D.; Michaels, V.; Dobryansky, M.; Levine, J.P.; Gurtner, G.C. Quantitative and reproducible murine model of excisional wound healing. Wound Repair Regen. 2004, 12, 485-492.

28. Wu, Y.; Chen, L.; Scott, P.G.; Tredget, E.E. Mesenchymal stem cells enhance wound healing through differentiation and angiogenesis. Stem Cells 2007, 25, 2648-2659.

(C) 2013 by the authors; licensee MDPI, Basel, Switzerland. This article is an open access article distributed under the terms and conditions of the Creative Commons Attribution license (http://creativecommons.org/licenses/by/3.0/). 